enforcement of legislative related to the five key risk factors for road traffic injuries which was investigated in GSRRS: speed, drink-driving, failure to use motorcycle helmets, seat-belts and child restraints. Since 1994, Croatia has implemented the National Road Safety Program, and in April of 2011 the same national draft program was adopted for the 2011-2020 period. The primary objective of the National Road Safety Program is to halve the number of road deaths by 2020 .

Conclusions Though significant progress has been achieved in road safety, more systematic work will be dedicated to elevating the level of road safety in line with international initiatives and national guidelines.

\section{AN ANALYSIS OF CAR CRASHES FATALITIES INVOLVING YOUNG DRIVERS IN QUEENSLAND AUSTRALIA}

Florin Oprescu, Bridie Scott-Parker, Jeanne Dayton. University of the Sunshine Coast

\subsection{6/injuryprev-2016-042156.889}

Background The road safety of children and young adults is an important topic across the globe due to the significant loss of life in this population due to road crash fatalities. To inform preventative interventions directed at high risk population it is important to explore the characteristics of fatal accidents involving young passengers and drivers.

Methods In Queensland, Australia, the Commission for Children and Young People and Child Guardian collects data pertaining to every registered child death ( $<18$ years), including deaths due to road crashes. Data for the period 1 July 2004 to 30 June 2012 was analysed with regards to demographic factors and variables such as age, gender, driver licence status and socioeconomic status, in order to provide insights into risk factors associated with traffic related child deaths where a driver 21 years or younger was involved.

Results Between 2004-2012, 100 children aged $<18$ years died in a road crash in Queensland where the driver was 21 years or younger, amounting to a total of 6283.5 disability adjusted life years. Risk factors included being male, living in a socioeconomically-disadvantaged location, driving inexperience and driving on the road before licensed. Ninety percent of fatalities were in the 15-17 years group and $68 \%$ of fatalities were male, suggesting gender-focused interventions that target male children, youth, and their parents deserve additional resourcing, especially in low resource areas. There is a clear need to engage youth and parents more broadly to reduce the risks associated with unlicensed driving, and to ensure that these youth have access to and are engaged with relevant programs in order to gain the maximum road safety benefits for themselves, their passengers, and other road users.

Conclusion Knowledge regarding contributors to and characteristics of crashes are vital for intervention efforts that prevent crash involvement of young people. For children to be safe on the road, the wider system which supports, regulates, and encourages their safety needs to operate effectively. Additional attention should be focused on environmental factors such as socio economic status and other social determinants of health in addition to driver-specific factors.

\section{0 "SEE ME SAVE ME" - IMPROVING THE SAFETY OF CYCLISTS}

Harpreet Singh Dhunna. Founder President Avoid Accident, India

\subsection{6/injuryprev-2016-042156.890}

Background Cyclists are hard to be seen on the roads during night, rain, fog and hazy weather. Mostly these vehicles do not have any lights which could alert the other drivers to feel their presence on roads. They especially cyclist became almost invisible during the night when head lights from other side makes driver almost blind.

Description Most of the Indian population lives in rural areas and small cities. Walking and cycling remain the dominant modes of transport in small cities and rural areas. ${ }^{1}$ The pedal bicyclist constitutes a significant share of total traffic on Indian roads accounting for $15-35 \%$ of total trips. ${ }^{2}$ The incidence of head injuries in cyclists ranges from $14-36 \%$ of the total injuries.

Method We have chosen one district to make the cyclists visible on the roads. The focus is on the labour class especially and the students riding it to schools. We involved traffic police and media to make it success. We choose the spot where the labour and workers with cycles are stationed.We fix high quality reflective on the cycles to make it visible on roads. And also we guide them about the driving precautions to be observed on roads riding at night and during fog.

Results Aids to improve pedestrians and cyclist visibility have been used to avert potential collisionsVisibility aids have the potential to increase visibility and enable drivers to detect pedestrians and cyclists earlier."Fluorescent materials in yellow, red and orange colours improve detection and recognition in the daytime. Retroreflective materials enhance recognition.

Conclusions Policy making and its enforcement is most important part of any project and which bring success to the project finally. Indian cycle industry have clear directions on reflective issues under Bureau of Indian Standards .Despite several submissions to Government we are finally moving to the Court of Justice to make it mandatory for cycle manufacturing industry to maintain the standards of reflectors.

\section{NOTES}

1 Gururaj G. Bangalore: Aditi Enterprises; 2011. Road safety in India: A frame work for action copyright: NIMHANS.

2 Mohan D. Delhi: Indian institute of technology; 2004. The Road ahead traffic injuries and fatalities in India.

\section{ANIMAL-DRAWN VEHICLES: ESTABLISHING A NATIONAL 'RECOMMENDED PRACTICE' TO IMPROVE THEIR VISIBILTY ON ROADS}

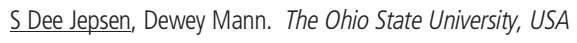

\subsection{6/injuryprev-2016-042156.891}

Background The horse is the main mode of transportation for Anabaptist populations and as a result, horse-drawn vehicles are involved in a high percentage of injury crashes with the motoring public. Members of the American Society of Agricultural and Biological Engineers established an Engineering Practice for animaldrawn buggies and wagons, and recently updated this Practice to include low-profile pony carts in 2014. The recommended 